\title{
Direct Determination of Benzamides in Serum by Column-Switching High-Performance Liquid Chromatography
}

\author{
Ryoko Chiba, ${ }^{* \dagger}$ Ayako Ogasawara, ${ }^{*}$ Teppei Kubo, ${ }^{*}$ Hiroyuki Yamazaki, ${ }^{* *}$ Masuo Umino, ${ }^{* *}$ \\ and Yoichi ISHIZUKA***
}

\author{
* Showa Pharmaceutical University, Machida 194-8543, Japan \\ **Scientific Instrument Division, Tosoh Co., 2743-1, Hayakawa, Ayase 252-1123, Japan \\ ***Teikyo University School of Medicine, Mizonokuchi Hospital 3-8-3, Kawasaki 213-0001, Japan
}

\begin{abstract}
A column-switching high-performance liquid chromatographic method with fluorescence detection was developed for the simultaneous determination of four benzamide-type anti-psychotic drugs: sulpiride, tiapride, sultopride and metoclopramide in human serum. In this method, a TSKgel Super-ODS column was used as an analytical column, and a TSKgel G 2000SW was prepared as a pretreatment column. Under the optimized analytical conditions, four benzamidetype anti-psychotic drugs were eluted within $18 \mathrm{~min}$. The detection limits $(S / N=3)$ for sulpiride, tiapride, sultopride and metoclopramide are $1 \mathrm{ng} / \mathrm{ml}, 4 \mathrm{ng} / \mathrm{ml}, 2 \mathrm{ng} / \mathrm{ml}$ and $0.5 \mathrm{ng} / \mathrm{ml}$, respectively. Finally, the method was applied to the determination of sulpiride in human serum samples obtained after a single oral dose of sulpiride.
\end{abstract}

(Received December 10, 2002; Accepted February 14, 2003)

Sulpiride, tiapride, sultopride and metoclopramide are substituted benzamides that exhibit anti-psychotic properties. They are antagonists of dopamine $\mathrm{D}_{2}$ receptors, which distinguish these compounds from other anti-psychotic agents. This singular feature may explain a very low incidence of adverse effects of these substances on the extrapyramidal system. In addition to their anti-psychotic action, substituted benzamides present anti-emetic, anti-depressive and anti-ulcer actions. ${ }^{1}$ A number of methods are available for analysis of benzamides in biological fluids, including spectrofluorometric detemination, ${ }^{2,3}$ gas chromatography (GC) ${ }^{4,5}$ high-performance liquid chromatography (HPLC) with UV detection ${ }^{6,7}$ and HPLC with fluorescence detection. ${ }^{8-11}$ The GC-mass spectrometric and HPLC-mass spectrometric methods have recently been reported. ${ }^{12,13}$ These methods are extremely sensitive, but require expensive investment. Meanwhile, although HPLC methods with UV and fluorescence detection are routinely used, these methods require complicated liquid-liquid or solid-phase extraction steps and/or several complicated clean-up steps. ${ }^{6-11}$ They are time-consuming and often poorly reproducible.

In this paper, we report a column-switching HPLC method for simultaneous determination of four benzamides in serum.

\section{Experimental}

Chemicals and materials

Sulpiride hydrochloride, tiapride hydrochloride and metoclopramide were purchased from Sigma (St. Louis, MO, USA). Sultopride was provided by Dainihon Pharmaceutical Co., Ltd. (Tokyo, Japan). HPLC-grade methanol and acetonitrile were obtained from Wako Pure Chemical Industries Ltd. (Osaka, Japan). All other reagents used were of analytical

\footnotetext{
† To whom correspondence should be addressed.

E-mail: chiba@ac.shoyaku.ac.jp
}

grade. Deionized water was purified by the Milli-Q system. Normal serum samples were obtained from Nippon Bio-supp. Center (Tokyo, Japan)

\section{Apparatus and HPLC conditions}

The column-switching HPLC consisted of two DP-8020 pumps, an autosampler AS-8020, a valve controller VC-8020, a column oven CO-8020, fluorescence spectrophotometer FS8020 and a system controller LC-8020 (Tosoh, Tokyo, Japan). A flow diagram of the column-switching system is shown in Fig. 1. A TSKgel Super-ODS column $(2.0 \mathrm{~mm}$ i.d. $\times 10 \mathrm{~cm}, 2.5$ $\mu \mathrm{m}$; Tosoh) was used as an analytical column, and a strong cation exchange column $(2.0 \mathrm{~mm}$ i.d. $\times 3.5 \mathrm{~cm})$ was used as a pretreatment column. It was prepared by chemically bonding TSKgel G2000SW (13 $\mu \mathrm{m}$; Tosoh) to the sulfone group. A mixture of acetonitrile, $150 \quad \mathrm{mmol} / \mathrm{l}$ sodium dihydrogenphosphate $(5: 95 \mathrm{v} / \mathrm{v})$ and $50 \mathrm{mmol} / \mathrm{l}$ sodium perchlorate (eluent $\mathrm{A}, \mathrm{pH}$ 6.8), a mixture of acetonitrile, 150 $\mathrm{mmol} / \mathrm{l}$ sodium dihydrogenphosphate $(12: 88 \mathrm{v} / \mathrm{v})$ and $50 \mathrm{mmol} / \mathrm{l}$ sodium perchlorate (eluent $\mathrm{B}, \mathrm{pH}$ 6.8), and a mixture of acetonitrile and $50 \mathrm{mmol} / \mathrm{l}$ phosphate buffer $(70: 30 \mathrm{v} / \mathrm{v})$ (eluent $\mathrm{C}, \mathrm{pH}$ 6.8) were used as the mobile phases. A mixture of acetonitrile and $1 \mathrm{mmol} / \mathrm{l}$ phosphate buffer $(5: 95 \mathrm{v} / \mathrm{v}, \mathrm{pH} 6.8)$ was used as the pretreatment solution. The flow rate of each of the two mobile phases (analysis and pretreatment) was 0.4 $\mathrm{ml} / \mathrm{min}$. The column temperature was maintained at $40^{\circ} \mathrm{C}$. The sample was diluted 5 -fold with $50 \mathrm{mmol} / \mathrm{l}$ sodium perchlorate to avoid lower recovery caused by binding of drugs to serum proteins. Then, five hundred microliters of this solution was injected onto the HPLC. Both analytical and pretreatment columns were re-equilibrated with the eluent $\mathrm{C}$ after every injection. Each drug was eluted by step gradients with the eluent $\mathrm{A}$ for $0.5 \mathrm{~min}$ and with the eluent $\mathrm{B}$ for $10 \mathrm{~min}$. The fluorescence intensity was monitored at $365 \mathrm{~nm}$ (emission) and $300 \mathrm{~nm}$ (excitation). The pretreatment procedure was run for $3.5 \mathrm{~min}$, which was long enough to remove high-molecular 


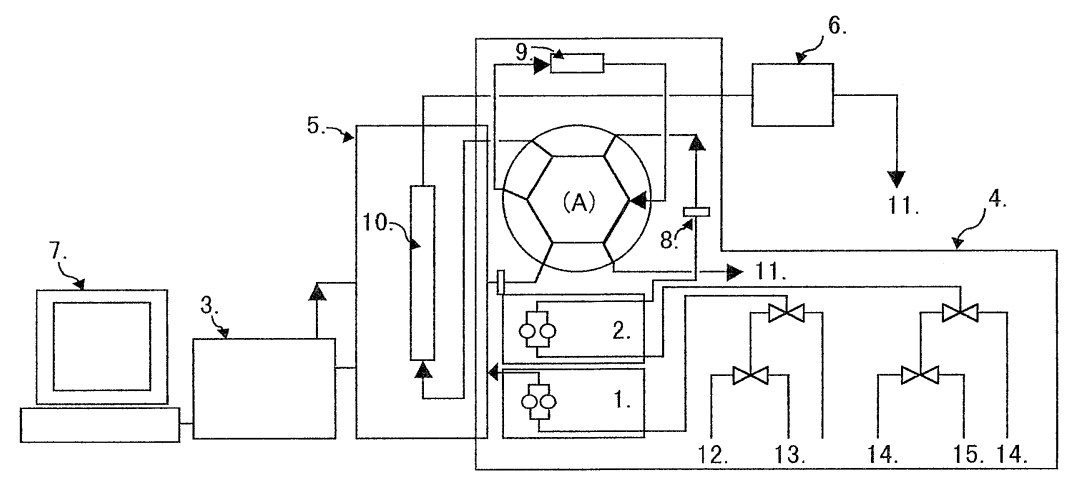

Fig. 1 Flow diagram of column switching HPLC. 1, pump-1; 2, pump-2; 3, auto sample injector; 4, switching valve; 5, column oven; 6, FS detector; 7, system controller; 8 , line filter $(1 \mu \mathrm{m}) ; 9$, precolumn; 10 , analytical column; 11, drain; 12, pretreatment eluent; 13, washing solution; 14, eluent-A; 15, eluent-B.

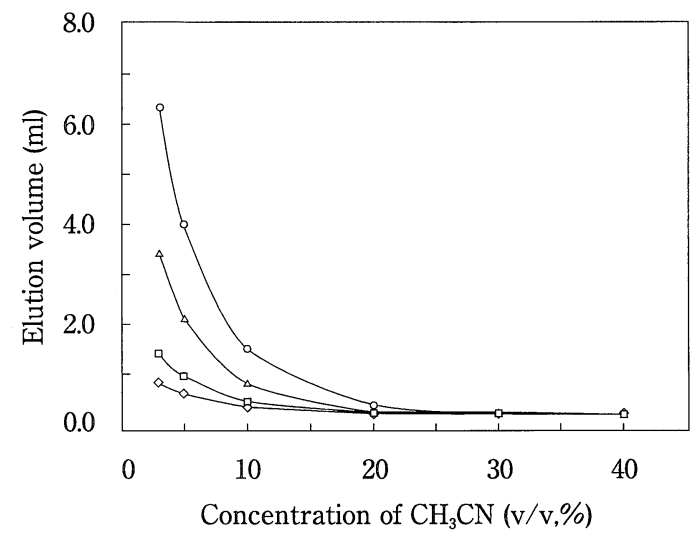

Fig. 2 Effect of $\mathrm{CH}_{3} \mathrm{CN}$ concentration in eluent on elution volume. Column, TSKgel Super-ODS $(2.0 \mathrm{~mm}$ i.d. $\times 10 \mathrm{~cm})$; flow rate, 0.4 $\mathrm{ml} / \mathrm{min}$ eluent, $\mathrm{CH}_{3} \mathrm{CN} / 50 \mathrm{mmol} / 1 \mathrm{NaH}_{2} \mathrm{PO}_{4}(x / y)$; detector, UV (210 $\mathrm{nm}$ ); injection volumn, $2 \mu \mathrm{l}$; temperature, $40^{\circ} \mathrm{C}$; sample, $\diamond$, sulpiride; $\square$, tiapride; $\triangle$, sultopride; $O$, metoclopramide.

weight components from the serum specimen. The connection time between the pretreatment column and the analytical column was $1 \mathrm{~min}$.

\section{Application of the method}

The method was used to quantitate the serum concentration of sulpiride administered in a single dose. The subjects were two healthy volunteers (male and female, 21 years old) who gave a written informed consent. The two subjects took $100 \mathrm{mg}$ of sulpiride in fasting state, under supervision of a doctor. A 10$\mathrm{ml}$ sample of blood was drawn at $0.5,1,2,3$ and $4 \mathrm{~h}$ after oral administration. Serum was separated by centrifugation at $3000 \mathrm{~g}$ for $15 \mathrm{~min}$ and stored at $-20^{\circ} \mathrm{C}$ until analysis.

\section{Standard solutions and calibration curves}

Each compound was dissolved in methanol to give a $100 \mu \mathrm{g}$ $\mathrm{ml}^{-1}$ stock solution, and the solutions were stored at $4^{\circ} \mathrm{C}$. Working standard solutions were freshly prepared daily by appropriate dilution of the stock solutions with deionized water. Each calibration curve was constructed by plotting the peak areas of each drug.

\section{Results and Discussion}

Optimization of pretreatment column

The column-switching HPLC method for drug analysis in serum generally uses a pretreatment column for deproteinization and selective adsorption of hydrophobic drugs. ${ }^{14-18}$ According to a report, the BSA-coated octadecyl reversed phase column (BSA-ODS column) is commonly chosen; it is filled with silica packing materials coated with denatured bovine serum albumin. Alternatively, an inner reversed phase column or a mixed functional column can be used for pretreatment (deproteinization and selective adsorption of the hydrophobic drugs). ${ }^{19,20}$ We evaluated several pretreatment columns in analysis of four kinds of drugs. To begin with, the BSAcovered reversed column, the BSA-ODS and the BSA-Octyl were tried as a pretreatment column. These pretreatment columns were found to be difficult to use for quantification of sulpiride, tiapride and sultopride. Because they had the same separation mode in the analytical column, the sample drugs in the standard serum were interfered with by low molecular weight components with strong hydrophobicity. On the other hand, thanks to their cationic nature, all four drugs were measurable with the cation exchange pretreatment column without any interference of the hydrophobic low molecular weight components in serum, because drugs were retained in the pretreatment column by ionic interactions. In this study, the cation exchange column was adopted as the pretreatment column. For the pretreatment solution, $1 \mathrm{mmol} / \mathrm{l}$ phosphate buffer ( $\mathrm{pH}$ 6.8)/acetonitrile (95/5) which can hold drugs in serum was used. ${ }^{21}$

\section{Optimization of analytical conditions}

Concentration of the organic solvent, $\mathrm{pH}$ and concentration of sodium perchlorate in the mobile phase were examined on the analytical column. Elution volume changes of the drugs are shown in Fig. 2. The elution volume decreased as the acetonitrile concentration increased. Figure 3 indicates the effect of the eluent $\mathrm{pH}$. Elution volumes did not change until $\mathrm{pH}$ 6, but began increasing at $\mathrm{pH}$ 6. This was because higher $\mathrm{pH}$ would have suppressed the dissociation of a pyrrolidine group or a diethylamino group, resulting in increased hydrophobicity of the drugs. Figure 4 indicates the effect of sodium perchlorate. The elution volume was elevated as the sodium perchlorate concentration increased and became constant beyond $50 \mathrm{mmol} / \mathrm{l}$. This was because the ion pair 
Table 1 Recovery, repeatability and reproducibility of standard and drugs spiked in serum by column-switching HPLC method

\begin{tabular}{|c|c|c|c|c|c|}
\hline \multirow{2}{*}{ Drug } & \multirow{2}{*}{$\begin{array}{l}\text { Spiked volume/ } \\
\mathrm{ng} \mathrm{ml}^{-1}\end{array}$} & \multicolumn{2}{|c|}{$\begin{array}{c}\text { Repeatability }(\mathrm{RSD}, \%, n=6) \\
{[\text { Recovery }[(\%, n=3)}\end{array}$} & \multicolumn{2}{|c|}{ Reproducibility (RSD, \% $n=3$ ) } \\
\hline & & Standard & Spiked serum & Standard & Spiked serum \\
\hline \multirow[t]{2}{*}{ Sulpiride } & 53 & $0.71[103]$ & $1.68[108]$ & 1.49 & 2.78 \\
\hline & 530 & $1.70[100]$ & $1.85[103]$ & 0.69 & 0.68 \\
\hline \multirow[t]{2}{*}{ Tiapride } & 52 & $2.05[110]$ & $2.76[109]$ & 1.40 & 2.09 \\
\hline & 520 & $1.52[102]$ & $1.42[104]$ & 1.61 & 1.12 \\
\hline \multirow[t]{2}{*}{ Sultopride } & 50 & $1.95[102]$ & $1.73[103]$ & 2.96 & 3.76 \\
\hline & 500 & $1.38[101]$ & $1.51[105]$ & 0.95 & 0.66 \\
\hline \multirow[t]{2}{*}{ Metoclopramide } & 53 & $1.45[114]$ & $2.23[128]$ & 0.69 & 1.24 \\
\hline & 530 & $0.71[103]$ & $1.37[119]$ & 3.35 & 0.87 \\
\hline
\end{tabular}

formed between sodium perchlorate and a pyrrolidine group or a diethylamino group made the mobile phase apparently neutral, and then the hydrophobic interaction was increased. As a result, the $\mathrm{pH}$ and sodium perchlorate concentration for the mobile phase were determined to be $\mathrm{pH} 6.8$ and $50 \mathrm{mmol} / \mathrm{l}$, respectively. The concentration of sodium dihydrogenphosphate was determined to be $150 \mathrm{mmol} / \mathrm{l}$ in consideration of the elution volume from the cation exchange pretreatment column. The concentration of acetonitrile in the mobile phase was determined for the step gradients from $5 \%$ (separation of sulpiride and tiapride) to $12 \%$ (sultopride and metoclopramide).

\section{Calibration curves}

Correlation equation and coefficient for each drug were: Sulpiride; $y=8.45 x+4.71, r^{2}=1.0000(53-1060 \mathrm{ng} / \mathrm{ml})$, tiapride; $y=3.00 x-0.42, r^{2}=1.0000(52-1040 \mathrm{ng} / \mathrm{ml})$, sultopride; $y=2.84 x+1.88, r^{2}=1.0000(50-1000 \mathrm{ng} / \mathrm{ml})$, metoclopramide; $y=14.80 x-30.47, r^{2}=0.9999(53-1060$ $\mathrm{ng} / \mathrm{ml}$ ) The detection limits (signal-to-noise ratio $=3$ ) for individual drugs were: $1 \mathrm{ng} / \mathrm{ml}$ (sulpiride), $4 \mathrm{ng} / \mathrm{ml}$ (tiapride), 2 $\mathrm{ng} / \mathrm{ml}$ (sultopride) and $0.5 \mathrm{ng} / \mathrm{ml}$ (metoclopramide). The sensitivity of sulpiride was approximately 10 times higher than those of the HPLC methods ${ }^{6-10}$ and was comparable to that reported by Tokunaga et al. ${ }^{11}$ Also, they use a smaller sample volume, which provided an advantage as compared with the previous method ${ }^{11}$ that required $1 \mathrm{ml}$ of plasma for drug analysis. On the other hand, the sensitivities of other compounds (tiapride, sultopride and metoclopramide) were much higher (from 2.5 to 14 times) than those obtained in fluorometric analysis. ${ }^{3}$

\section{Recovery and repeatability}

Results for recovery, repeatability (within-day precision) and reproducibility (between-day precision) are shown in Table 1. Recovery was determined by comparing the peak areas obtained from samples with those obtained after direct injection of drugs dissolved in mobile phase. Triplicate analysis was performed for each drug. Each drug was well recovered in $100-128 \%$. Repeatability and reproducibility of this method were studied. Repeatability was evaluated by injecting each of two concentrations of a drug six times. Reproducibility was also evaluated for at least 5 days by injecting the same samples three times a day. The relative standard deviation (RSD) did not exceed $2.76 \%$ in repeatability and $3.76 \%$ in reproducibility. The results showed that the on-line HPLC system was satisfactory for all the benzamide-type anti-psychotic drugs studied. Figure 5 shows the typical chromatograms obtained with a standard mixture of the drugs (A) and with a blank serum spiked with sulpiride, tiapride, sultopride and metoclopramide

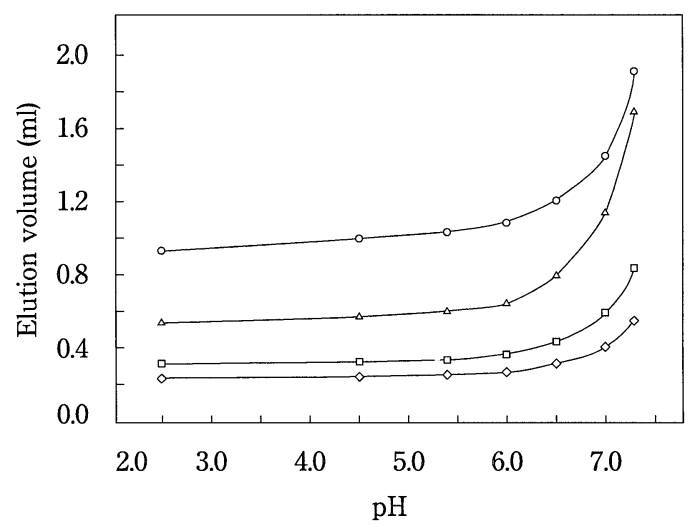

Fig. 3 Effect of $\mathrm{pH}$ in eluent on elution volume. Eluent: $\mathrm{CH}_{3} \mathrm{CN} / 50$ $\mathrm{mmol} / 1 \mathrm{NaH}_{2} \mathrm{PO}_{4}\left(\mathrm{pH}_{\mathrm{x}}\right)(10 / 90)$; other conditions as in Fig. 2 .

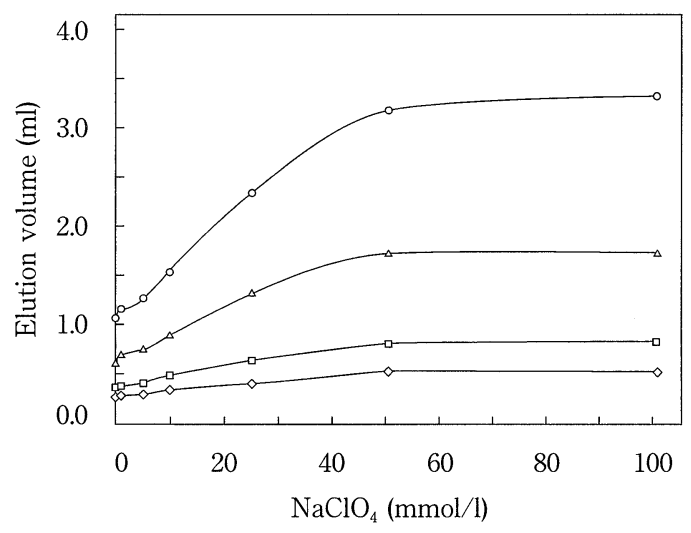

Fig. 4 Effect of $\mathrm{NaClO}_{4}$ concentration in eluent on elution volume. Eluent: $\mathrm{CH}_{3} \mathrm{CN} / 50 \mathrm{mmol} / 1 \mathrm{NaH}_{2} \mathrm{PO}_{4}(10 / 90)+x \mathrm{mmol} / \mathrm{l} \mathrm{NaClO}_{4}$ other conditions as in Fig. 2.

(B). The retention times of sulpiride, tiapride, sultopride and metoclopramide were $8.01,11.61,15.31$ and $17.58 \mathrm{~min}$, respectively. No interfering peaks were observed in the chromatograms.

\section{Application of the method}

In order to evaluate the proposed method for clinical use, it was applied to the monitoring of drug concentrations in serum samples obtained after a single oral dose of sulpiride $(100 \mathrm{mg})$. Figure 6 shows the chromatogram of the serum sample from 

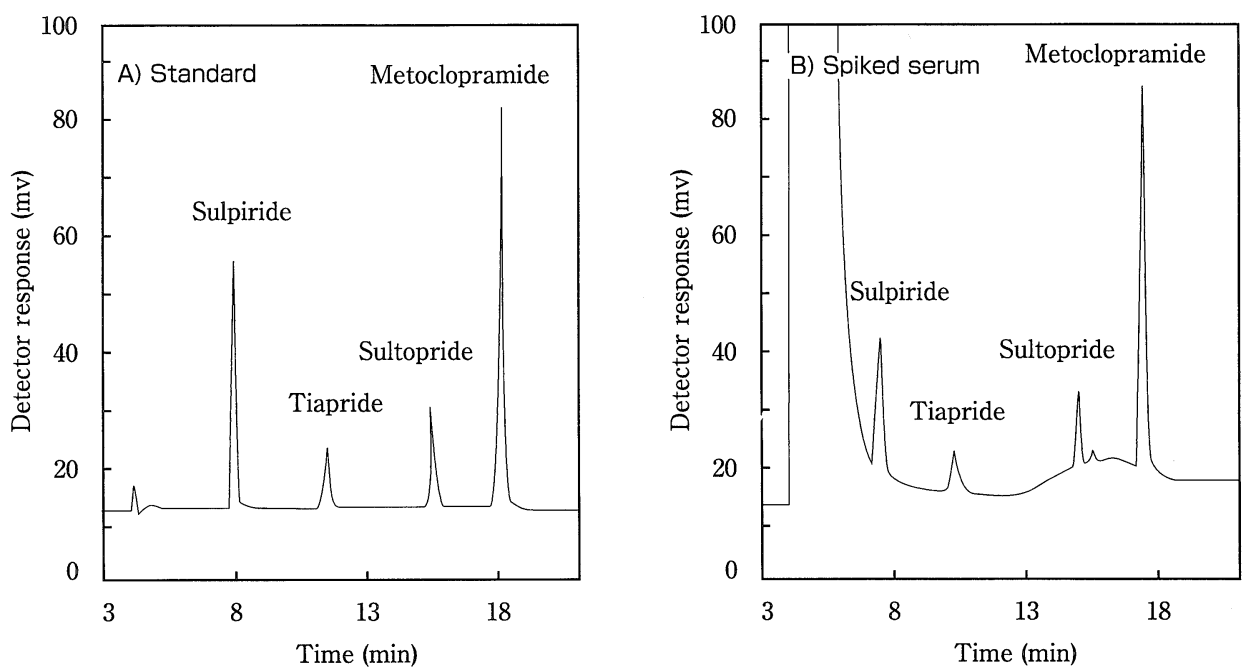

Fig. 5 Chromatograms of standard sample and drugs spiked in human serum by column-switching HPLC system. Conditions: analytical column, TSKgel Super-ODS $(2.0 \mathrm{~mm}$ i.d. $\times 10 \mathrm{~cm})$; pretreatment column, cation exchange resin $(2.0 \mathrm{~mm}$ i.d. $\times 3.5 \mathrm{~cm})$; flow rate, $0.4 \mathrm{ml} / \mathrm{min}$ (analysis and pretreatment); eluent-A, $150 \mathrm{mmol} / 1 \mathrm{NaH}_{2} \mathrm{PO}_{4} / \mathrm{CH}_{3} \mathrm{CN}(95 / 5)+50 \mathrm{mmol} / 1 \mathrm{NaClO}_{4}$, eluent-B, $150 \mathrm{mmol} / \mathrm{l} \mathrm{NaH} \mathrm{PO}_{4} / \mathrm{CH}_{3} \mathrm{CN}(88 / 12)+$ $50 \mathrm{mmol} / 1 \mathrm{NaClO}_{4}$; washing solvent, $50 \mathrm{mmol} / \mathrm{l}$ phosphate buffer $(\mathrm{pH} 6.8) / \mathrm{CH}_{3} \mathrm{CN}(30 / 70)$; pretreatment solvent, $1 \mathrm{mmol} / \mathrm{l}$ phosphate buffer $\left(\mathrm{pH}\right.$ 6.8) $\mathrm{CH}_{3} \mathrm{CN}(95 / 5)$; detector, Ex. $300 \mathrm{~nm}$, Em. $365 \mathrm{~nm}$; sample volume, $500 \mu \mathrm{l}$ (2-fold dilution); temperature, $40^{\circ} \mathrm{C}$; sample: standard sample (A), drugs spiked in human serum (B). concentration: sulpiride $\left(53 \mathrm{ng} \mathrm{ml}^{-1}\right)$, tiapride $\left(52 \mathrm{ng} \mathrm{ml}^{-1}\right)$, sultopiride $\left(50 \mathrm{ng} \mathrm{ml}^{-1}\right)$, metoclopramide $\left(53 \mathrm{ng} \mathrm{ml}^{-1}\right)$.
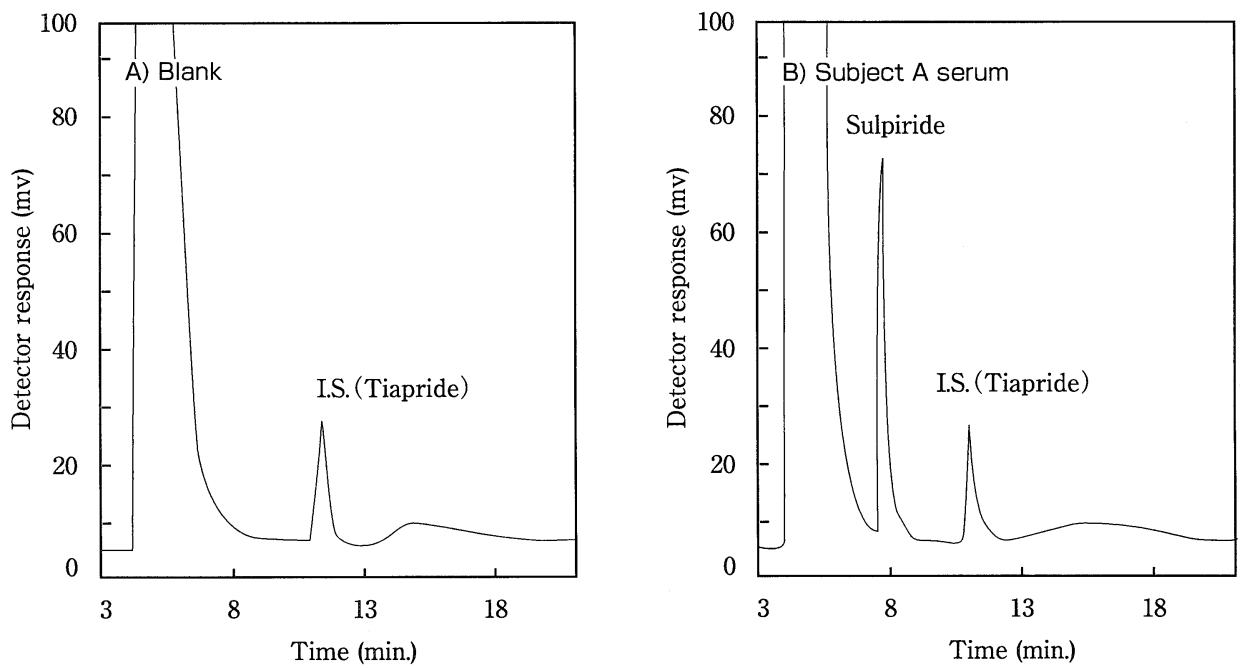

Fig. 6 Chromatograms obtained with (A) blank serum and (B) serum after oral administration of sulpiride (subject A); HPLC conditions as in Fig. 5.

Subject A. As a result, sulpiride was well separated from tiapride (I.S.) and was not interfered with by coexisting substances in the serum. Figure 7 shows the time-concentration curves obtained from the serum samples. The concentrations reached a maximum value at $2-4 \mathrm{~h}$ after oral administration, and thereafter gradually decreased. While intra-individual variations were found in serum sulpiride levels (range of 375 $466 \mathrm{ng} / \mathrm{ml}$ ), these results were close to reference values. ${ }^{22,23}$

The column-switching HPLC using a high performance semimicro column (TSKgel Super-ODS) and a pretreatment column containing a strong cation-exchange silica could simultaneously analyze four benzamide-type anti-psychotic drugs in serum within only $18 \mathrm{~min}$. The recovery, repeatability and reproducibility performance was satisfactory. These results suggest that this method is useful in simple routine analysis of benzamide-type anti-psychotic drugs.

\section{References}

1. K. Fujii, "Iyakuhin no Kagaku to Sayou", 1993, Yakuji Jihousya, Tokyo, 36.

2. T. Kleimola, O. Leppanen, J. Kanto, R. Mantyla, and E. Syvalahhti, Ann. Clin. Res., 1976, 8, 104.

3. M. Buna, J. J. Aaron, P. Prognon, and G. Mahuzier, Analyst, 1996, 121, 1551.

4. S. Staveris, L. Jung, G. Jamet, and J. C. Koffel, J. Chromatogr., 1985, 79, 338. 


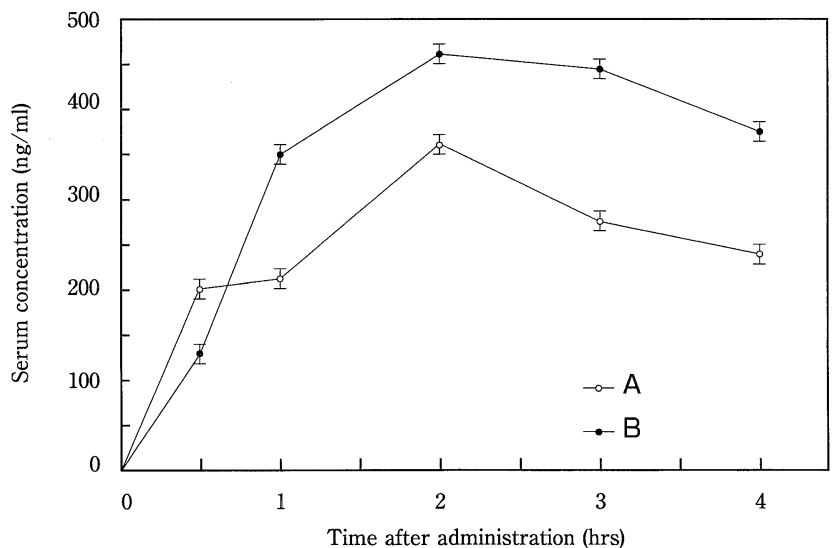

Fig. 7 Serum concentration-time profiles of sulpiride after single $100 \mathrm{mg}$ oral dose of sulpiride to two healthy volunteers. Symbol: open, subject A (female); closed, subject B (male). HPLC conditions as in Fig. 5. Each plot and vertical line represents the mean $(n=3)$ and standard deviation, respectively.

5. A. Frgerio and C. Pantarotto, J. Chromatogr., 1977, 361, 130.

6. T. R. Norman, R. H. James, and M. S. Gregory, J. Chromatogr., 1986, 375, 197.

7. F. Bressolle and J. Bres, J. Chromatogr., 1985, 341, 391.

8. K. Nishihara, Y. Kohida, and Z. Tamura, Chem. Pharm. Bull., 1983, 31(11), 4144.

9. G. Alfredsson, G. Sedvall, and F. A. Wiesel, $J$
Chromatogr., 1979, 164, 187

10. P. Nicolas, F. Fauvelle, and A. Ennachachibi, $J$. Chromatogr., 1986, 381, 393 .

11. H. Tokunaga, K. Kudo, N. Jitsufuchi, Y. Ohtsuka, and T. Imamura, J. Chromatogr. B, 1997, 691, 203.

12. P. P. Rop, M. H. Sournac, I. Elie, J. Burle, and M. Fornaris, J. Anal. Toxicol., 1999, 23, 294.

13. M. Rittner, F. Pragst, W.-R. Bork, and J. Neumann, J. Anal. Toxicol., 2001, 25, 115.

14. I. Morita, T. Masujima, H. Yoshida, and H. Imai, Anal. Biochem., 1981, 118, 142.

15. I. Morita, T. Masujima, H. Yoshida, and H. Imai, J. Pharm. Dyn., 1982, 5, s-29.

16. H. Yoshida, I. Morita, T. Masujima, and H. Imai, Chem Pharm. Bull., 1982, 30, 3827.

17. H. Yoshida, A. Nagami, I. Morita, T. Masujima, and H. Imai, J. Pharm. Dyn., 1983, 7, s-18.

18. I. Morita, T. Masujima, H. Yoshida, and H. Imai, Anal. Biochem., 1985, 151, 358 .

19. I. H. Hagestam and T. C. Pinkerton, Anal. Chem., 1985, 57, 1757.

20. T. Kanda, H. Kutsuna, Y. Ohtsu, and M. Yamaguchi, J. Chromatogr. A, 1994, 672, 51.

21. T. Kanda and Y. Ohtsu, Chromatography, 1998, 19, 4, 332.

22. S. Banba, H. Yamamoto, R. Yano, K. Tan, and S. Otaki, Fujisawa Pharmaceutical. Co., unpublished data (CLR840044).

23. S. Morita, A. Hirohashi, A. Nagata, K. Kimura, and H. Miyawaki, Fujisawa Pharmaceutical. Co., unpublished data (CLR840045). 